\title{
BARRAGENS DE REJEITOS DE MINERAÇÃO NO BRASIL: UMA OBSERVAÇÃO A PARTIR DAS RELAÇÕES ENTRE DIREITO, CIÊNCIA E POLÍTICA
}

\author{
Giselle Marie Krepsky ${ }^{1}$ \\ Sabrina Lehnen Stoll ${ }^{2}$
}

\section{RESUMO}

O artigo apresenta um estudo da correlação entre os sistemas do Direito, da Ciência e da Política, ante ao enfrentamento das questões de segurança das barragens de rejeitos de mineração no Brasil. O problema é compreender sob quais condições desastres de barragens representam uma possibilidade de aprendizagem voltada para a prevenção. A partir da teoria de Niklas Luhmann e releituras contemporâneas, utilizou-se o método indutivo e as técnicas de pesquisa bibliográfica, documental e jurisprudencial. Conclui-se que houve aprendizagem com os eventos catastróficos denotando que é possível sofisticar a legislação por meio das irritações sistêmicas advindas da Ciência e do Direito.

Palavras-chave: Barragens de rejeitos de mineração; Aprendizagem sistêmica; Ciência; Direito; Política.

\section{MINING WASTE DAMS IN BRAZIL: AN OBSERVATION FROM THE RELATIONSHIP BETWEEN LAW, SCIENCE AND POLITICS}

\begin{abstract}
The article presents a study of the correlation between the systems of Law, Science and Politics, when facing the issues of safety of mining tailings dams in Brazil. The problem is to understand under what conditions dams disasters represented a possibility of learning aimed at prevention. Based on Niklas Luhmann's theory and contemporary reinterpretations, the inductive method and bibliographic, documentary and jurisprudential research techniques were used. We conclude that there was learning from catastrophic events, showing that it is possible to sophisticate legislation through systemic irritations arising from Science and Law. Keywords: Mining tailings dams; Systemic learning; Science; Right; Politics.
\end{abstract}

\footnotetext{
${ }^{1}$ Doutora em Direito Público - UNISINOS. Professora do Mestrado em Direito FURB. Líder do Grupo de Pesquisas CNPq: Justiça, Educação e Ciência e membro do Grupo Direitos Fundamentais, Cidadania e Justiça.

${ }^{2}$ Mestranda em Direito FURB. Especialista em Direito Público, pela FURB-ESMESC. Membro do grupo de Pesquisas Justiça, Educação e Ciência. Bolsista FURB. E-mail:sstoll@ furb.br
} 


\section{INTRODUÇÃO}

As recentes catástrofes envolvendo o rompimento de barragens de rejeitos de mineração das cidades de Mariana (05 de novembro de 2015) e Brumadinho (29 de janeiro de 2019), ambas localizadas no estado de Minas Gerais e de propriedade da empresa Vale S.A, criaram um impacto negativo que gerou a necessária discussão e comunicação entre os sistemas da Ciência, do Direito e da Política. ${ }^{3}$

O objetivo da pesquisa é a análise da correlação entre esses sistemas na gestão de risco e no enfrentamento às questões de segurança das barragens de mineração. $O$ foco principal é apresentar as possíveis correlações para que, compreendendo tal dinâmica, se possa dar maior atenção às irritações sistêmicas mais eficazes.

Desta forma, o estudo sobre o tema visa contribuir para os debates acerca do emprego da teoria dos sistemas no sentido de buscar melhorias nas estruturas para a produção de precaução e prevenção dos riscos no que diz respeito à segurança de barragens de mineração. E, no caso de ocorrência do desastre, como o Direito, pode aprender com o sistema da Ciência, para que, no meio da complexidade destes eventos, dar uma melhor resposta, mitigando para a sociedade as consequências decorrentes das catástrofes.

No contexto em que a comunicação/informação técnica orienta tanto as atividades tecnológicas quanto as ações decorrentes do mau uso delas, torna-se extremamente relevante compreender como estas comunicações científicas (predominantemente os pareceres e perícias) são recepcionadas pelo Direito e pela Política (legislativo). Neste ponto, a relação entre os sistemas sob comento se estreita. De um lado a Ciência possui a função de construir e comunicar conhecimento com base na sua própria estrutura que é voltada preponderantemente para a cognição e a aprendizagem, respeitando seu código: verdade/não verdade sobre as coisas. De outro, o Direito é encarregado de estabilizar as expectativas sociais a partir da aplicação do que é positivado pelo Sistema da Política e para o qual também são delegadas responsabilidades de permissão e impedimento de ações tecno-científicas produzidas pelo Sistema da Ciência e pela sociedade em geral. Assim, pode-se observar que o sistema do

\footnotetext{
${ }^{3}$ Como o viés da pesquisa é voltado primordialmente para a capacidade da comunicação científica interferir nas ações do Direito e da Política, não se inclui na análise o sistema da Economia, o qual, sabe-se tem elevado poder de influência sistêmica em ações tecnológicas.
} 
Direito pode interferir no sistema da Ciência, já que aquele apresenta uma função normativa e reguladora. No entanto, a Ciência, também pode interferir no sistema do Direito e na própria Política, porquanto Direito e Política não possuem em suas estruturas elementos para determinar e orientar sobre questões predominantemente técnicas das áreas da biologia, botânica, geologia, física, química, entre tantas outras que dizem respeito à prática de mineração.

Compreender estas relações e as possíveis interferências destes sistemas permite prospectar quais políticas públicas e, especificamente por meio de quais organizações que as fazem operar, é possível uma ação mais contundente a fim de evitar tragédias, melhorar a resposta a elas e por fim, aprimorar todos os sistemas envolvidos de modo a garantir a exploração ambiental de forma segura e sustentável.

O estudo se enquadra na linha direito ambiental, agrário e socioambientalíssimo, que tem como objetivo a busca por um meio ambiente sadio e ecologicamente equilibrado de uma forma transgeracional. Optou-se pelo método indutivo utilizando-se as técnicas de revisão bibliográfica e documental, a partir da teoria sistêmica de Niklas Luhmann, bem como a ressignificação realizada por Gunther Teubner e autores contemporâneos.

\section{BARRAGENS DE REJEITOS DE MINERAÇÃO NO BRASIL: ANTES E DEPOIS DOS DESASTRES EMBLEMÁTICOS}

As barragens de rejeitos de mineração existem com o propósito de armazenar o material inutilizado no processo de extração do minério de ferro. Na legislação federal anterior aos eventos não existia previsão de um tipo específico de construção de barragem de rejeitos, ficando a critério da empresa a escolha, desde que cumpridos os requisitos de licenciamentos e planos de segurança.

A Lei $\mathrm{n}^{\mathrm{O}}$ 12.334/2010 (BRASIL, 2010) previu no texto original que o empreendedor é o responsável legal pela segurança da barragem, cabendo-lhe o desenvolvimento de ações para garanti-la, sendo igualmente o responsável por alimentar a ANM (Agência Nacional de Mineração) através do SGBM (Sistema Integrado de Gestão de Segurança de Barragens de Mineração) com as informações técnicas sobre a segurança e estabilidade das barragens.

Já a Lei Complementar $n^{0}$ 140/2011 (BRASIL,2011) confere aos Estados e Municípios a prerrogativa de concessão do Licenciamento ambiental (competência 
administrativa), sendo que no estado de minas Gerais, quem concede a licença ambiental para construção é a Fundação Estadual do Meio Ambiente (FEAM/MG) e o Departamento Nacional de Produção Mineral (DNPM), órgão vinculado à Agência Nacional de Mineração e ao Ministério de Minas e Energia que será o fiscalizador em conjunto com os demais órgãos ambientais das demais esferas do governo.

A Política Nacional de Segurança de Barragens (PNSB) foi instituída através da Lei $\mathrm{n}^{\mathrm{o}} 12.334 / 2010$, definindo, em seu artigo $2^{\circ}$, inciso I, barragem como qualquer estrutura em um curso permanente ou temporário de água para fins de contenção ou acumulação de substâncias líquidas ou de misturas de líquidos e sólidos, compreendendo o barramento e as estruturas associadas" (BRASIL, 2010).

Há que se esclarecer que existem barragens no sentido amplo (gênero) sendo as barragens de rejeitos de mineração uma das espécies existentes. De acordo com a PNSB, as barragens são classificadas de acordo com a categoria do risco, dano potencial associado, sendo este, alto, médio ou baixo. (BRASIL, 2010).

A PNSB autoriza as empresas mineradoras a utilizar três métodos de construção de barragens de rejeitos, quais sejam: alteamento a montante, alteamento a jusante e alteamento de centro. O Brasil, historicamente, tem utilizado o método de alteamento a montante, que além de ser mais barato, verificou-se ser o que possuí um risco maior de rompimento. $\mathrm{O}$ método alteamento a montante é feito a partir da construção de um dique inicial, utilizando o próprio rejeito depositado com alteamentos sucessivos. Estes alteamentos vão sendo feitos no sentido contrário ao montante de água, após, a barragem necessita de rejeito mais grosso para a construção do maciço. O método de alteamento para jusante é considerado o mais convencional, construído em solo compacto, e os alteamentos são realizados no sentido da água a jusante, método considerado de média segurança e pouco econômico. Já o método de alteamento por linha de centro é considerado o mais caro e seguro de todos. Possui estabilidade superior à da barragem alteada a montante. Inicialmente é construído um dique de partida, e, conforme são realizados alteamentos de ampliação, são construídos novos diques sobre os rejeitos anteriores, oferecendo maior estabilidade de sustentação e equilíbrio.

Este método foi constatado pelo sistema da Ciência, através de laudos técnicos fornecidos por engenheiros e especialistas, como o mais inseguro e barato de construção, tendo em vista a maior probabilidade de ruptura, pois o próprio rejeito é que segura a estrutura dos alteamentos. (SANTOS; CURI; SILVA, 2010). Nota-se que este método de construção 
foi o utilizado nas barragens de Mariana e Brumadinho, que romperam e geraram desastres emblemáticos.

$\mathrm{Na}$ fase de resposta a uma catástrofe, ou seja, nos momentos de maior desestabilização após o evento como os rompimentos de barragens de rejeitos, o sistema do Direito exerce um papel de protagonismo na orientação das medidas a serem adotadas e na imposição de deveres de proteção e cuidado às instituições competentes, a fim de que tais instituições estejam efetivamente preparadas para o exercício das respostas emergenciais, com delimitação precisa de competências, interações e atuação compartilhada (CARVALHO, 2017, p.256).

Primeiramente há que se fazer uma divisão das competências encontradas na Constituição Federal (administrativas e legislativas), pois o meio ambiente está inserido em ambas. Sob o prisma da dogmática ambiental as competências constitucionais excluem os municípios de legislar sobre o tema, e atribuem à União, Estados, e Distrito Federal capacidade para tal. Ainda sobre o tema, o artigo 225 da Constituição Federal consagra o meio ambiente ecologicamente equilibrado como um direito fundamental, sendo dever de todos defendê-lo e preservá-lo. (BRASIL, 1988).

No que se refere à gestão e fiscalização de barragens de rejeitos de minério de ferro, a PNSB estruturou uma política, de âmbito federal, a qual discorre sobre a segurança e fiscalização das referidas estruturas, e, na condição de política pública, criou o Sistema Nacional de Informações Segurança de Barragem - (SNISB).

O órgão fiscalizador das barragens de rejeitos, segundo a PNSB, é o Departamento Nacional de Produção Mineral (DNPM), vinculado à Agência Nacional de Mineração (ANM) e ao Ministério de Minas e Energia (MME), e que atua em conjunto com os demais órgãos ambientais das demais esferas do governo.

No Brasil, a Lei Complementar $n^{\circ}$ 140/2011 (BRASIL, 2011) conferiu aos estados e municípios a prerrogativa de concessão do licenciamento ambiental (competência administrativa), e, nesse sentido, conclui-se que a licença para a construção e o controle ambiental são de competência do órgão estadual, e a fiscalização de segurança das barragens é de competência do órgão federal (DNPM) em primeiro plano, com a colaboração dos demais órgãos integrantes no SISNAMA. (BRASIL, 2011).

Em relação à prevenção de desastres, a lei que criou a PNSB que determina em seus artigos $9^{\circ}, 10$ e 16 que a empresa deverá realizar inspeções regulares, apresentando a 
qualificação da equipe técnica responsável ao órgão fiscalizador. (BRASIL, 2010). A legislação deixa a cargo da empresa contratar a equipe técnica que irá elaborar os laudos de segurança para apresentá-los ao órgão fiscalizador, e este, por sua vez, tem a responsabilidade de incluir os dados fornecidos pela empresa no SNISB.

Ainda, a portaria $\mathrm{n}^{\mathrm{o}}$ 70.389, de 17 de maio de 2017 da DNPM (BRASIL, 2017), com o intuito de reforçar a segurança, obriga toda empresa a ter um plano de segurança de barragem, determinando em seu art. $8^{\circ}$ que "o Plano de Segurança da Barragem é instrumento da Política Nacional de Segurança de Barragens, de implementação obrigatória pelo empreendedor, cujo objetivo é auxiliá-lo na gestão da segurança da barragem".

Percebe-se, assim, uma complexa rede de organizações estatais (Sistema da Política - Administração Pública) que atuam parcialmente sobre regulação e fiscalização de tal atividade, e, acrescente-se que boa parte de tais operações dependem da própria autoorganização, autorregularão e autoprodução de informações técnicas por parte das empresas que exploram o minério.

A legislação existente até a ocorrência dos desastres emblemáticos de Mariana e Brumadinho, ambos localizados no Estado de Minas Gerais, falharam em vários pontos, destacando-se as principais: a) A legislação federal existente era controversa quanto a competência fiscalizadora dos órgãos existentes, constando que há uma evidente abstenção estatal no que se refere a fiscalização destas barragens de rejeitos de mineração, posto que, conforme a descrição da norma àquela época, a fiscalização e prevenção eram transferidas para as próprias empresas de mineração, gerando um problema muito grave inclusive de autoregulamentação. b) Constatou-se que a legislação federal conferia uma liberdade para a empresa escolher o método de construir a barragem de rejeitos, e que dos métodos descritos na legislação o denominado por alteamento era muito arriscado e perigoso.

Por fim, a fim de reduzir e prevenir desastres emblemáticos, após o evento ocorrido na Barragem B1, da cidade de Brumadinho-MG, a ANM publicou, no dia 15 de fevereiro de 2019, a Resolução $N^{o} 4$, que posteriormente se transformou na Lei $n^{\circ} 14.066 / 2020$, com a finalidade de tornar proibido este método de construção por alteamento em todo o território nacional, bem como determinando a desativação das construções existentes. (BRASIL, 2020)

Nota-se que a alteração legislativa da norma federal ocorreu como consequência dos processos de aprendizagem que os desastres emblemáticos anteriores proporcionaram aos 
sistemas da Ciência e do Direito, gerando forte consequência no sistema da Política, tanto que houve alteração legislativa da norma federal.

Tais alterações podem ser resumidas na tabela que segue.

Tabela 1 - Quadro resumo de modificações legislativas

\begin{tabular}{|c|c|c|}
\hline $\begin{array}{c}\text { Regulamentação antes dos } \\
\text { eventos de } 2015 \text { e } 2019\end{array}$ & $\begin{array}{c}\text { Modificações após Mariana } \\
\qquad(2015)\end{array}$ & $\begin{array}{l}\text { Modificações após } \\
\text { Brumadinho (2019) }\end{array}$ \\
\hline $\begin{array}{l}\text { Lei } \mathrm{n}^{\circ} \text { 12.334/2010 - Estabelece } \\
\text { a Política Nacional de } \\
\text { Segurança de Barragens }\end{array}$ & $\begin{array}{llcr}\text { Edição da } & \text { Portaria } & \mathrm{n}^{\circ} \\
70.389 / 2017 & \text { - Cria o Cadastro } \\
\text { Nacional de } & \text { Barragens } & \text { de } \\
\text { Mineração } & \text { e } & \text { o } & \text { Sistema } \\
\text { Integrado } & \text { de } & \text { Gestão } & \text { em } \\
\text { Segurança } & \text { de } & \text { Barragens } & \text { de } \\
\text { Mineração } & & & \end{array}$ & $\begin{array}{l}\text { Proibição de construção ou o } \\
\text { alteamento de barragem de } \\
\text { mineração pelo método a } \\
\text { montante (Lei no 14.066/2020). }\end{array}$ \\
\hline $\begin{array}{l}\text { Lei Complementar } \mathrm{n}^{\circ} \text { 140/2011, } \\
\text { confere aos estados } \\
\text { municípios o licenciamento } \\
\text { ambiental nas obras de } \\
\text { barragens de rejeitos de } \\
\text { mineração. }\end{array}$ & $\begin{array}{l}\text { Lei } 13.575 / 2017 \text {, que cria a } \\
\text { Agência Nacional de Mineração } \\
(\mathrm{ANM})\end{array}$ & \\
\hline & $\begin{array}{l}\text { Lei } \mathrm{n}^{\circ} 21.972 / 2016 \text {, que trata } \\
\text { sobre o Sistema Estadual do } \\
\text { Meio Ambiente e Recursos } \\
\text { Hídricos - SISEMA. Estado de } \\
\text { Minas Gerais. }\end{array}$ & \\
\hline
\end{tabular}

Fonte: Elaborada pelas autoras

No contexto de complexidade social, estes eventos emblemáticos demonstram que o sistema do Direito não estava completamente preparado para decidir sobre eventuais desastres envolvendo barragens de mineração. Nesse sentido, é necessário que exista uma constante interação e comunicação entre os sistemas da Ciência, Direito e Política, para que ocorram modificações concretas e efetivas nas legislações como medida de prevenção com o escopo de evitar danos transgeracionais que possam ocorrer em função das atividades tecno-científicas do ramo da mineração. 


\section{O PAPEl dOS SISTEMAS DO DIREITO, DA CIÊNCIA E DA POLÍtica NA GESTÃO DAS BARRAGENS DE MINERAÇÃO}

$\mathrm{Na}$ sociedade moderna antropocêntrica e complexa, a materialização dos riscos e danos causados pela interação homem, tecnologia, ciência e meio ambiente, tem se distribuído de forma não excludente, gerando uma cadeia de eventos cada vez mais incertos.

Diante desta incerteza, o risco inserido na modernidade é um produto social. Uma das externalidades dos riscos são os desastres como os citados nesta pesquisa. Estes desastres fizeram emergir a necessária reflexão sobre a construção de um Direito com a função de efetiva gestão de catástrofes.

Para Carvalho (2013, pp.31-32):

Os desastres são fenômenos extremos capazes de atingir a estabilidade
sistêmica social, num processo de irradiação e retroalimentação de suas
causas e efeitos policontextualmente (econômicos, políticos, jurídicos,
científicos). [...] Os desastres estão diretamente ligados à ideia de eventos
capazes de desestabilizar um sistema ao ponto de que perca a capacidade de
diferenciação funcional e de operacionalizar e assimilar aquele evento
rapidamente. Tal colapso gera, por evidente, uma incapacidade de
assimilação e recuperação rápida, sendo, por esta razão, a resiliência um
conceito central na descrição das catástrofes.

Assim, observa-se que os desastres emblemáticos que ocorreram nas barragens de rejeitos de mineração desestabilizaram os sistemas da Ciência, pois houve a necessidade de recorrer aos laudos técnicos e científicos na busca do motivo da ocorrência recorrente de tais desastres; do Direito, no sentido da tomada de decisões jurídicas eficazes para mitigar ou diminuir a problemática e da Política no que tange à análise da legislação existente ser ou não suficiente para gerar efeitos das decisões mediante as provocações tanto do Direito quanto da Ciência.

Observa-se, assim, a necessidade de uma aprendizagem pelos sistemas envolvidos em relação ao risco criado pelas empresas de mineração.

Nos ensinamentos de Carvalho (2013, p. 34):

Assim, uma "semântica das catástrofes" é desenvolvida a partir da ênfase na necessidade de antecipação aos perigos (alheios a qualquer controle) ou riscos (passíveis de alguma dimensão de controle pelo sistema) catastróficos. 
Constatações de risco são a forma sob a qual ressurgem-nos centros da modernização - na economia, nas ciências naturais, nas disciplinas técnicas a ética e, com ela, também a filosofia, a cultura e a política. Constatações de risco são uma ainda desconhecida e subdesenvolvida simbiose de ciências naturais e humanas, de racionalidade cotidiana e especializada, de interesse e fato. Ao mesmo tempo, não são nem apenas uma e nem apenas a outra coisa. São ambas e sob uma nova forma. Já não se podem mais especializar, isolar uma da outra, desenvolvendo e fixando seus próprios padrões de racionalidade.

Nesse contexto, destaca-se a importância do sistema da Ciência quando se fala na prevenção do risco, visto que, após pesquisas e emissão de laudos técnicos, este sistema ditará a verdade sobre aquele ou outro risco. Mas neste ponto, deve-se perceber que apesar de a Ciência ser uma autoridade, nem sempre consegue ser de fato efetiva, pois o científico está em constante modificação e atualização e o Sistema da Ciência, apesar de ter o compromisso com a verdade (código duro do sistema) não tem obrigação temporal e deve estar sempre em abertura cognitiva. Ou seja, sempre poderá comunicar diferente a partir de novos programas (teorias) e, por conseguinte, modificar a comunicação classificada como verdade ou não verdade sempre. E mesmo verificada a importância deste sistema, ele não pode ser o único a decidir sobre os riscos, pois os outros sistemas devem estar sempre em observação (neste caso hetero-observação) constante para que os eventos externos sejam assimilados sofisticando suas futuras comunicações. Acrescente-se ainda que, na era das incertezas a Ciência também tem seu papel impactado, pois ela passa mais a ofertar probabilidades do que certezas.

Nesse tocante, Carvalho (2013, pp.35-36) assevera que:

A pretensão de racionalidade das ciências de determinar objetivamente o
teor de risco do risco refuta-se a si mesma permanentemente: ela baseia-se
por um lado, num castelo de cartas e conjecturas especulativas e move-se
unicamente no quadro de asserções de probabilidade, cujos prognósticos de
segurança não podem, a bem da verdade, ser refutados sequer por acidentes
reais. Por outro lado, é preciso ter assumido um ponto de vista axiológico
para chegar a falar de risco com alguma propriedade. Constatações de risco
baseiam-se em possibilidades matemáticas e interesses sociais, mesmo e
justamente quando se revestem de certeza técnica. O envolvimento científico
com os riscos do desenvolvimento industrial continua igualmente a referir-se
a horizontes axiológicos e expectativas sociais, da mesma forma como,
inversamente, a discussão e percepção sociais dos riscos em relação aos
argumentos científicos.

Nos ensinamentos de Luhmann (1998, p. 48), “complejidad [...] significa coacción de la selección. Coacción de la selección significa contingencia y contingencia significa riesgo". Significa que a complexidade e as várias alternativas de ação diante delas implica numa 
necessária escolha e toda escolha implica risco, posto que se escolhe uma entre tantas outras possibilidades que se deixam de lado. Isso é contingência, pois sempre poderia ser diferente. Cabe ao Direito, assim como aos demais sistemas determinantes em uma sociedade de risco, perquirir a melhor escolha possível. Assim, no Estado Democrático de Direito Constitucional, as escolhas ambientais devem pautar-se na Constituição, sobretudo.

Nesse sentido, além de coexistirem entre si, cada um com suas próprias características, se verifica que os sistemas sob comento podem, e devem, se interrelacionarem, com o objetivo de aprimorarem suas próprias estruturas, reduzindo a complexidade da sociedade e as suas que são constantemente criadas. De acordo com Luhmann (1991, p. 91), “os sistemas estão enclausurados em suas próprias operações e sendo assim, eles não podem conter estruturas, podem apenas, construí-las por meio de sua autoorganização".

É aí que as organizações que estruturam cada um dos sistemas ganham destaque, pois é por meio delas que cada um externaliza suas operações (comunicam). A partir de suas organizações serão feitas as observações que os sistemas necessitam, para após, a partir de acoplamentos e assimilações, possibilitar as necessárias alterações para a mitigação e gerenciamento dos riscos.

As organizações são as estruturas burocráticas encarregadas de tomar decisões coletivas a partir da programação e do código dos sistemas. Os sistemas adquirem a sua identidade numa permanente diferenciação com o ambiente e com os outros sistemas, graças às decisões das organizações. $\mathrm{O}$ Poder Judiciário pode ser visto como uma organização voltada à consecução das decisões do sistema do Direito. (ROCHA, 2013, p. 35).

Para Luhmann (1985 apud KREPSKY, 2017), esse processo de diferenciação que também é móvel e circunstancial é provocado também pelo afastamento entre a legislação e a jurisprudência. A jurisprudência trata da exposição, manutenção e sanção do direito vigente, ou seja, das expectativas normativas por meio das quais será manifestada a determinação e menos a assimilação das transgressões. Se as expectativas juridicamente normatizadas são transgredidas, cabe ao juiz resguardar a expectativa. Por outro lado, o legislador, tanto normas quanto fatos que transgridam as expectativas são observados sob outro prisma que estará mais sujeito à aprendizagem por meio da cognição. Tudo que diz respeito à aceitação, cumprimento, transgressão, custo, conflitos comportamentais que decorrem da normatividade pode ser de alguma forma registrado pelo legislador. 
Ele (o legislador) pode e até mesmo deve demonstrar estar disposto a corrigir expectativas. Ele é o destinatário da vontade de mudar, a instância da apreensão institucionalizada no direito. Ele tem a possibilidade de autocorrigir-se e espera-se que ele a utilize e ainda se responsabilize pela omissão de correções, pela rejeição da assimilação apreensiva. [...] No interesse de uma maior capacidade de negociação, os processos legislativos devem estar livres da pressão imediata das frustrações e da necessidade de expor-se normas já transgredidas; por outro lado eles devem poder tratar as normas jurídicas como ainda sujeitas à decisão, tendo então que adequar-se às condições muito mais complexas de uma escolha entre diversas normas jurídicas possíveis. (LUHMANN, 1985, p. 39).

Portanto, evidencia-se que as comunicações tanto da Ciência quanto do Direito diante de eventos sejam eles catastróficos ou não, podem interferir ou estimular operações diferenciadas visando tanto a precaução quanto a mitigação de danos.

Nesse sentido, é possível identificar o sistema do Direito atuando (comunicando/decidindo) na prevenção de danos e na orientação futura:

AGRAVO DE INSTRUMENTO. AÇÃO CIVIL PÚBLICA. DIREITO AMBIENTAL. POSSIBILIDADE DE REATIVAÇÃO DA "MINA DEL REY". TUTELA DE URGÊNCIA. NÃO COMPROVAÇÃO DOS REQUISITOS AUTORIZADORES. DECISÃO REFORMADA. [...] DIREITO AMBIENTAL. BEM IMÓVEL PROTEGIDO, EMBORA SEM TOMBAMENTO. ESSENCIALIDADE DA PRESERVAÇÃO. FORMAS DIVERSAS DE PROTEÇÃO, POR MEDIDAS DE CAUTELA. PRINCÍPIO DA PREVENÇÃO. - Um bem de valor histórico, cultural ou artístico, deve ser resguardado como de interesse público. A decisão agravada apenas determinou que a agravante realize a elaboração de um plano de manejo com aprovação do órgão competente, pelo que não se justifica a revogação da liminar. A afirmação de que o empreendimento está em fase final de implantação não se pode sobrepor à lei ambiental, devendo ser evitados acidentes como o que recentemente ocorreu na própria Mariana e em Brumadinho. - Depois de uma tragédia não haverá o que preservar, tornando premente a invocação do princípio da prevenção, com destaque para o que dispõe o artigo 216 da CF, cuja simples leitura deixa explicitada a importância constitucional direta dessa regra, segundo a qual o Poder Público, com a colaboração da comunidade, promoverá e protegerá o patrimônio cultural brasileiro, por meio de inventários, registros, vigilância, tombamento e desapropriação, e de outras formas de acautelamento e preservação, inclusive, naturalmente, as formas que o Poder Judiciário adotar como cautelares. Ou seja, a proteção constitucional é ampla e não se restringe a bens inventariados ou tombados, mas a qualquer bem de valor histórico reconhecido (par. $1^{\circ}$ ). - Segundo a CF (ver artigo 170, VI), "a atividade econômica não pode ser exercida em desarmonia com os princípios destinados a tornar efetiva a proteção ao meio ambiente", como já decidiu o STF (ver ADI 3.540-MC, Rel. Min. Celso de Mello, DJ de 3.2.2006). [...] O princípio da prevenção o que visa é evitar um perigo concreto (já comprovado cientificamente como possível), o que é o caso, pois os perigos 
da mineração são muito conhecidos em Minas Gerais e pela própria recorrente. Já o princípio da precaução pretende impedir um evento futuro e incerto, ou um perigo abstrato (não certo, mas possível), como ocorre, por exemplo, com os alimentos transgênicos, a respeito dos quais se admite a possibilidade de causarem mal à saúde humana, mas sem que se tenha certeza absoluta sobre esse fato. (TJMG, 2018, online).

E ainda:

EMENTA: AGRAVO DE INSTRUMENTO - DIREITO TRIBUTÁRIO MUNICÍPIO DE RIO DOCE - AÇÃO ANULATÓRIA DE DÉBITO FISCAL - TAXA DE ALVARÁ DE LICENÇA PARA CONSTRUÇÃO DE OBRA - EMPREENDIMENTO MINERÁRIO -SUSPENSÃO DA EXIGIBILIDADE MEDIANTE DEPÓSITO JUDICIAL DO VALOR INTEGRAL DO TRIBUTO - TUTELA DE URGÊNCIA - DEFERIMENTO - PRESENÇA DOS PRESSUPOSTOS ELENCADOS PELO ART.300 DO NCPC - DECISÃO MANTIDA. [...] AGRAVO DE INSTRUMENTO. RETIRADA DE REJEITOS DE MINÉRIO DO RIO DOCE. OPERAÇÃO SUJEITA A CONTROLES PÚBLICOS QUE NÃO SE ESGOTAM NO ÂMBITO FINANCEIRO/TRIBUTÁRIO. NECESSIDADE DE CAUTELAS E OBSERVÃNCIA DO PRINCÍPIO DA PREVENÇÃO. RECURSO PROVIDO. - O rompimento da barragem da mineração em Mariana foi um fato gravíssimo e novas tragédias ambientais devem ser prevenidas, não sendo recomendável a concessão de novo alvará de construção sem a prévia fiscalização do Município agravante e do próprio Ministério Público. - Não existe no caso qualquer demonstração de que baste à concessão do alvará o pagamento da taxa questionada. Segundo esclarece o Município, a questão é muito mais complexa, pois envolve inclusive a possibilidade de destruição de imóveis de valor cultural tombados, o que, em tese, pode até constituir crime, segundo as leis de proteção ao patrimônio cultural. - Para além da taxa, segundo sustenta o Município, há a necessidade de uma efetiva fiscalização para avaliar a possibilidade da construção e, consequentemente, da expedição do alvará. O pagamento da taxa é apenas uma das várias condicionantes a serem observadas. - As diligências (decorrentes do poder de polícia) pretendidas pelo Município devem ser permitidas -- e não interditadas -- pelo Judiciário. - O depósito judicial da taxa, se impede a penalização da agravada, não garante a observância das normas de prevenção de impacto ambiental e proteção da área a qual os rejeitos serão transportados. - $\mathrm{O}$ nosso ordenamento jurídico consagra o princípio da prevenção, associado, constitucionalmente, aos conceitos fundamentais de equilíbrio ecológico e desenvolvimento sustentável; o primeiro significa a interação do homem com a natureza, sem danificar-lhe os elementos essenciais. O segundo prende-se à preservação dos recursos naturais para as gerações futuras. É um compromisso de ordem intergeracional e possui berço constitucional. (TJMG, 2018, online).

Assim, não obstante haja a coexistência com o risco pode-se encontrar maneiras de geri-lo, pois sob a ótica dos sistemas existe uma identificação para cada área do conhecimento, e no gerenciamento do risco busca-se uma interação entre os Sistemas, que 
apesar de sua autopoiese, permitem irritações por meio de suas comunicações. Isso porque, são abertos e voltados para aprendizagem e fechados em seus próprios códigos.

Em relação aos desastres nas barragens de rejeitos de minérios de Mariana e Brumadinho foi possível identificar que ocorreu a comunicação entre os sistemas, o que gerou ações e medidas posteriores na tentativa de precaução de eventos futuros.

Desta comunicação realizada, os resultados da análise sobre o tema prevenção de riscos - extraídos com base nos conhecimentos técnicos do sistema da Ciência - geraram consequências no sistema da Política, o que se constata pela movimentação no campo legislativo, especialmente pela elaboração de legislação com proibição de construção de barragens utilizando o método de alteamento, entre outras modificações.

Segundo Pardo (2013, p. 32), essa comunicação entre os sistemas da Ciência e do Direito é que vai regular e, inclusive, decidir as situações de incerteza científica.

El nuevo entorno y ambiente que ha propiciado um considerable desapoderamiento - ya veremos si justificable y com que alcance - de las instancias jurídicas y políticas habilitadas por el Derecho y um correlativo avance de la ciencia em la toma de decisiones está marcado por la expansión de la incertidumbre em muchas frentes, también y destacadamente la incertidumbre que rodea la ciencia y la tecnologia, dejando a las instancias jurídicas y políticas de deciosión em uma situación muy delicada y compleja. (PARDO, 2013, p. 11).

Desta comunicação advêm os resultados da análise sobre o tema prevenção de riscos e precaução de danos futuros, extraídos com base nos conhecimentos técnicos do Sistema da Ciência, e que geram consequências no Sistema da Política. Esta dependência do meio e de outros sistemas ocorre com restrições e através do que Luhmann (2010, p. 139) chama de irritação (perturbação, estimulação). Ou seja, visualiza-se que os desastres emblemáticos irritaram os sistemas da Ciência, Direito e Política, criando processos de aprendizagem.

No que se refere a essa "irritação", Beck vai um pouco além, pois, ao tratar do efeito reflexivo, esclarece que a reflexividade e a reflexão se diferem, visto que o fato de se ter o conhecimento científico não significa dizer que será feita a reflexão sobre a reflexividade das ações práticas, ou seja, não garante que se irá refletir sobre as consequências, danos e riscos gerados pelos nossos atos (BECK, 2018).

A partir disso pode emergir uma catarse social, incluindo reflexo, reflexividade e reflexão. $\mathrm{O}$ choque antropológico induz uma espécie de memória coletiva compulsiva do fato de que decisões e erros do passado estão contidos naquilo a que nos vemos expostos; de que mesmo o grau mais elevado de retificação institucional não é nada senão uma retificação que 
pode ser anulada, um modo de ação emprestado, que pode e deve ser modificado se levar ao autocomprometimento (BECK, 2018, p.161).

Nesse sentido, um dos primeiros reflexos dos desastres ocorridos foi a constatação de que a legislação existente, apesar de o texto da PNSB objetivar a necessária prevenção de acidentes, destacou apenas a regulamentação das estruturas de barragens já existentes, dando ênfase às fases de preparação e resposta na perspectiva de ocorrência de um desastre. Ou seja, foi necessário surgir a "irritação" para haver uma interação/comunicação entre os sistemas da Ciência, do direito e, por fim da Política.

É por isso que uma solução apontada por Teubner (1989, p. 191 e ss.) para as dificuldades de regulação pelo Direito migra da tentativa de interferência direta para a possibilidade de comunicação por meio de organizações que integram esses sistemas, já que eles não têm capacidade de agir coletivamente, mas, apenas, por meio das suas organizações específicas. A partir do sistema social global, existem subsistemas e estes são autopoiéticos, ou seja, estes sistemas se autorregulam, são autônomos na sua existência, linguagem e comunicação.

Sobre o tema lecionam Rocha et al. (2009, p. 19):

Por isso, pode-se dizer que existem sistemas sociais da Política, da Economia e do Direito, porque, como sistemas funcionalmente diferenciados fornecem critérios de identificação para cada uma dessas áreas do conhecimento. Como tudo isso está dentro da sociedade, todas as áreas do conhecimento surgem da sociedade e têm, por isso, autonomia, mas uma autonomia que existe na diferença dela com a sociedade. E não é uma diferença pronta, acabada, pois se elabora em operações. Trata-se de uma diferença que se constrói constantemente numa dinâmica que exige a autorreprodução de cada sistema, a partir de seus próprios elementos, diferenciando-se dos outros sistemas e se diferenciando dos ambientes, num processo constante.

E para que haja uma interação entre eles há que se observar os acoplamentos estruturais. Aproxima-se uma estrutura do sistema através de suas organizações acoplando-se, abrindo o sistema para comunicação que deve ser feita com o sistema desejado e após fechase o sistema.

Neste ponto, organizações têm uma finalidade muito específica, como assinalam Rocha e Carvalho (2012) as organizações como, por exemplo, o Poder Judiciário, IBAMA e Agências Nacionais, que se constituem formas de acoplamento estrutural privilegiadas, possibilitam que as observações e descrições efetivadas orientem as decisões a serem tomadas pelos sistemas que as envolvem a partir da produção de sentido específica para cada um deles. 
Há que se observar que ambos descendem do sistema social global, e que a partir deste não há uma hierarquia entre os sistemas. Não tendo hierarquia quando um sistema se comunica com outro deve haver um grau de ponderação, visto que um definitivamente não detém maior conhecimento do que o outro dentro da sua própria autopoiese.

Por isso Teubner (1989) ainda ressalta que ao levar em consideração que o modelo proposto de autopoiese leva a clausura dos sistemas ao extremo, é praticamente impossível que um sistema participe na autopoiese de outro. Da mesma forma ocorre com o meio envolvente, posto que permanece inacessível para as operações do sistema, devendo reconstruí-lo internamente. Sendo assim, uma consequência severa com relação ao Direito é a de que os modelos legislativos não se perfectibilizam por meio de esquemas simples de inputoutput, apenas com troca simples e direta de informações entre ele e a sociedade. Não há relação linear de causalidade como se as normas produzissem automaticamente mudanças sociais. Igualmente não é o processo legislativo uma espécie de emissor de informações para serem cumpridas pelos demais sistemas sociais, já que não é o legislador quem vai organizar os sistemas regulados e para os quais a norma pretende atingir. São os próprios subsistemas regulados que vão selecionar as informações por ele prestadas e criar a sua própria ordem internamente. Isto está diretamente relacionado com a autonomia do sistema que permite a regulação e se identifica como a autorreprodução, autodescrição e autoidentificação.

Por isso, para Teubner (1989, p. 150):

[...] o direito e os sistemas sociais regulados podem apenas (co-)evoluir em isolamento recíproco, num processo de co-evolução 'cega' que está fora do alcance do controlo do primeiro e que é aparentemente disciplinado pela dupla seletividade da autopoiesis do sistema jurídico e do sistema regulado. Os actos jurídicos devem 'satisfazer' a autopoiesis de ambos os sistemas: disto depende o respectivo sucesso regulatório.

O processo de aprendizagem que ocorre nos sistemas através de observação e posterior comunicação que irá ocorrer por meio de suas organizações será mais eficiente e mais rápido, pois irão se comunicar apenas o ponto específico de cada sistema para formar uma decisão mais acertada e próxima da realidade do problema.

\section{CONSIDERAÇÕES FINAIS}

Sobre a gestão dos desastres de barragens de rejeitos de minério de ferro constatou-se que, no que se refere ao risco e seu gerenciamento, era concreto, previsível e mensurável por 
parte da Empresa Vale S/A e dos órgãos públicos, e, em que pese existir um órgão que classifica as barragens por nível do risco, a classificação adotada não previu que um dos principais riscos na ocorrência de uma catástrofe poderia advir justamente da parte técnica de como ela é construída. Ou seja, as barragens haviam sido construídas antes da legislação da Política Nacional de Segurança de Barragens, e grande parte das barragens existentes no Brasil foi construída pelo método de alteamento, que se constatou mais tarde pelo sistema da Ciência como ineficaz e com potencial ao desastre.

Desta forma, a legislação classificou de forma objetiva as barragens em que ocorreram os desastres como de baixo risco, sem levar em consideração critérios subjetivos, que posteriormente foram aclarados pelo sistema da Ciência. Ainda se verificou que em várias catástrofes não foram adotadas medidas de prevenção e fiscalização eficazes.

Os processos de aprendizagem em relação ao sistema do Direito foram concluir que houve a irresponsabilidade legislativa pela falta de definição competências, falta de fiscalização estatal na Política Nacional de Segurança de Barragens e a autorregularão, fatos estes que implicaram na diluição de competências e na fixação de nexos de causalidade. Esta fragilidade de gestão que permeou o sistema do Direito potencializou, sobremaneira, o risco de tragédias.

A partir do sistema da Ciência a conclusão foi no sentido de corrigir erros de ordem técnica no que se refere à construção e manutenção das barragens de rejeitos de mineração, bem como de que o método de construção por alteamento é obsoleto e de alto risco de ocorrência de desastres.

No sistema da Política houve modificações legislativas consideráveis, criação de novas legislações com melhor efetividade na gestão e mitigação dos riscos, sendo que neste ramo a principal alteração foi a proibição legislativa de construção de barragem de rejeitos de minério de ferro pelo método por alteamento.

Diante disso, se constatou através do sistema da Ciência que após vários desastres industriais no ramo da mineração o principal motivo foi a utilização do método de construção por alteamento, desta forma, as tragédias que ocorreram apontam uma percepção do risco em meio a uma sociedade complexa em que esses fatos irritaram os sistemas da Ciência, da Política e do Direito, gerando a necessidade de comunicação entre ambos. E ainda, verificouse que no contexto de complexidade social, após os desastres emblemáticos ocorridos nos 
últimos tempos, o sistema do Direito não estava completamente preparado para decidir sobre eventuais desastres envolvendo barragens de rejeitos de minério de ferro.

Nesta toada, fica evidenciada a necessidade de um horizonte normativo com bases estruturantes à crise do Antropoceno, que se dará no contexto de uma maior interação entre os sistemas do Direito, da Ciência e da Política, o que seria fundamentalmente capaz de apoiar e gerir os riscos no enfrentamento dos desastres na sociedade complexa de risco. Assim, as medidas de responsabilidade e prevenção estariam pautadas no equilíbrio ecológico e a norma constitucional, bem como as infraconstitucionais, teriam como base estruturante a responsabilidade advinda do campo da Ciência, todavia, atuando na prevenção e não na mitigação.

O que se percebe é que organizações funcionalmente criadas para controlar e gerir os riscos foram omissas, deixando de adotar ações preventivas e refutando a responsabilização em casos de desastres ocorridos.

Ainda sobre os processos de aprendizagem, verifica-se a necessidade da interação entre os sistemas da Ciência, do Direito e da Política para a obtenção de práticas bemsucedidas de gerenciamento do risco, registrando-as a fim de formar um conhecimento institucional e sistematizado a fim de sofisticar cada um dos Sistemas que estão envolvidos diretamente no controle do manejo desta atividade.

Por fim, ainda que os desastres possibilitem o surgimento de processos de aprendizagem, o ideal é a antecipação ao risco. Trata-se de uma intrínseca articulação entre lei, regulamentação administrativa, decisões judiciais e comunicação científica, o que só ocorrerá com maior êxito a partir do aprimoramento das estruturas de cada um dos sistemas e suas respectivas organizações que atuarão em acoplamento.

\section{REFERÊNCIAS}

BECK, Ulrich. A metamorfose do mundo: novos conceitos para uma nova realidade. 1. ed. Rio de Janeiro: Zahar, 2018.

BRASIL. Constituição da República Federativa do Brasil de 1998. Disponível em: http://www.planalto.gov.br/ccivil_03/constituicao/constituicao.htm. Acesso em: 29 de março de 2021. 
BRASIL. Lei $\mathbf{N}^{\mathbf{0}} \mathbf{1 2 . 3 3 4}$, de 20 de Setembro de 2010. Disponível em: http://www.planalto.gov.br/ccivil_03/_Ato2007-2010/2010/Lei/L12334.htm. Acesso em: 29 de março de 2021.

BRASIL. Lei $\mathbf{N}^{\mathbf{0}}$ 12.608, de 10 de Abril de 2012. Disponível em: http:// http:// http://www.planalto.gov.br/ccivil_03/leis/lcp/lcp140.htm. Acesso em: 29 de março de 2021.

BRASIL. Lei $\mathbf{N}^{\mathbf{0}}$ 140, de 08 de Dezembro de 2011. Disponível em: http:// http://www.planalto.gov.br/ccivil_03/_ato2011-2014/2012/lei/112608.htm. Acesso em: 29 de março de 2021.

BRASIL. Lei $\mathbf{N}^{\mathbf{1}}$ 14.066, de 30 de Setembro de 2020. Disponível em: http://www.planalto.gov.br/ccivil_03/_ato2019-2022/2020/lei/L14066.htm. Acesso em: 29 de março de 2021.

BRASIL. Portaria $\mathbf{N}^{\mathbf{7}} \mathbf{7 0 . 3 8 9}$, de 17 de Maio de 2017. Disponível em: https://www.gov.br/anm/pt-br/assuntos/barragens/portaria-dnpm-no-70-389-de-04-de-marçode-2021. Acesso em: 04 de março de 2021.

BRASIL. Lei $\mathbf{N}^{\circ} \mathbf{2 1 . 9 7 2}$ de 21 de Janeiro de 2016. Disponível em: http://www.siam.mg.gov.br/sla/download.pdf?idNorma=40095 . Acesso em: 04 de março de 2021.

CARVALHO, Délton Winter de. Direito dos Desastres. São Paulo: Editora Revista dos Tribunais, 2013.

CARVALHO, Délton Winter de. Gestão jurídica ambiental. São Paulo: Editora Revista dos Tribunais, 2017.

KREPSKY, Giselle Marie. O DIREITO E A CIÊNCIA. Decisão judicial e produção científica sob uma observação sistêmica. Rio de Janeiro: Lumen Juris, 2017.

LUHMANN, Niklas. Introdução à teoria dos sistemas. Tradução de Ana Cristina Arantes Nasser. 2.ed. Petrópolis: Vozes, 2010.

LUHMANN, Niklas. Sociologia do Direito II. Rio de Janeiro: Tempo Brasileiro, 1985.

LUHMANN, Niklas. Sistemas Sociales: Lineamentos para uma teoría general. México: Anthropos, 1998.

PARDO, José Esteves; PALACIOS, Javer Tejada. Ciencia y Derecho: La nueva divisíon de poderes. Madrid: Fundación Coloquio Jurídico Europeo, 2013.

ROCHA, Leonel Severo; KING, Michael; SCHWARTZ, Germano. A verdade sobre a autopoiese no Direito. Porto Alegre: Livraria do Advogado, 2009. 
ROCHA, Leonel Severo; CARVALHO, Délton Winter de. Policontexturalidade jurídica e Estado ambiental. In: ROCHA, Leonel Severo; DUARTE, Francisco Carlos (Coordenadores). Direito Ambiental e Autopoiese. Curitiba: Juruá, 2012, p. 25-45.

ROCHA, Leonel Severo. Da epistemologia jurídica normativista ao construtivismo sistêmico II. In: ROCHA; SCHWARTZ; CLAM. Introdução à teoria do sistema autopoiético do direito. 2.ed. Porto Alegre: Do Advogado, 2013.

SANTOS, DAM dos; CURI, A.; SILVA, JM da. Técnicas para a disposição de rejeitos de minério de ferro. In: VI Congresso Brasileiro de Mina a Céu Aberto (CBMina), Belo Horizonte. 2010.

TJMG. AGRAVO DE INSTRUMENTO: AICv 1.0521.17.002093-2/001. Relator: Desembargador Luís Carlos Gambogi, 5ª CÂMARA CÍVEL, 2018. Disponível em https://www5.tjmg.jus.br/jurisprudencia/ementaSemFormatacao.do?procAno=17\&procCodig $\mathrm{o}=1 \&$ procCodigoOrigem $=521 \&$ procNumero $=2093 \&$ procSequencial $=1 \&$ procSeqAcordao $=0$. Acesso em 04/04/2021.

TJMG. AGRAVO DE INSTRUMENTO: AICv 01741445220198130000. Relator: Desembargador Moacyr Lobato, $5^{\text {a }}$ CÂMARA CÍVEL, 2019. Disponível em https://www5.tjmg.jus.br/jurisprudencia/ementaSemFormatacao.do?procAno=18\&procCodig $\mathrm{o}=1 \&$ procCodigoOrigem $=400 \&$ procNumero $=5029 \&$ procSequencial $=1 \&$ procSeqAcordao $=0$. Acesso em 04/04/2021.

TEUBNER, Gunther. O direito como sistema autopoiético. Tradução de José Engrácia Antunes. Lisboa: Fundação Calouste Gulbenkian, 1989. 